\title{
Evaluation of anatomical and morphological characteristics of the nasopalatine canal in a Turkish population by cone beam computed tomography
}

\author{
S. Hakbilen, G. Magat \\ Necmettin Erbakan University Dentistry Faculty, Konya, Turkey
}

[Received: 8 December 2017; Accepted: 19 January 2018]

\begin{abstract}
Background: The aim of this study was to analyse as three dimensions the anatomical and morphometric dimensions of nasopalatine canal (NPC) in the coronal, axial and sagittal directions using cone beam computed tomography (CBCT) and to evaluate the effect of age, gender and maxillary dental status on NPC and buccal bone thickness (BBT).

Materials and methods: In this study, CBCT data of the 619 individuals aged between 17 and 86 years were examined retrospectively with respect to dimensions and anatomic variations of the NPC and BBTs. The correlation of age, gender, and status of edentulism of anterior maxilla with all the variables were evaluated. Results: The NPC and BBT showed important variability in terms of morphology and dimensions. Morphological assessment of NPC revealed that $26.17 \%$ of NPCs were conical shape, $24.71 \%$ of canals were hourglass-shaped, $16.80 \%$ of canals were cylindrical shaped, $15.83 \%$ of canals were funnel-like shaped, $11.14 \%$ of canals were banana-like shaped, and $5.33 \%$ of canals were tree branch-like shaped. Males and females showed significant differences in the length of the NPC and BBTs in the sagittal sections. There were significant differences between age and BBTs. In addition, the length of NPC and BBTs were statistically different according to dental status.

Conclusions: These anatomical changes in terms of dimensional and morphological parameters revealed the importance of three-dimensional imaging. Dentists should know and consider the variations in this canal in order to avoid possible complications during anaesthesia and surgical procedures which were applied to the maxillary anterior region. More precautions should be taken during surgical procedures in females, elderly and edentulous patients. (Folia Morphol 2018; 77, 3: 527-535)
\end{abstract}

Key words: anatomy, nasopalatine canal, buccal bone thickness, cone beam computed tomography

\section{INTRODUCTION}

Dental aesthetics has become an important issue in dentistry with implant applications for the last 15-20 years. Patients have begun to prefer implant therapy due to aesthetic concerns rather than function. Failure of implant therapy usually leads to removal of the implant, followed by complicated tissue and additional bone procedures [6]. Nerve tissue and

Address for correspondence: Assist. Prof. Dr. G. Magat, Department of Oral and Maxillofacial Radiology, Faculty of Densitry, Necmettin Erbakan University, Konya, Turkey, tel: +90-505-945-6157, e-mail: gul_dent@hotmail.com 
implant contact may cause osseointegration failure or sensory dysfunction [26].

The most pronounced anatomical formation in the anterior maxillary region is the nasopalatine canal (NPC), also known as the incisive canal or anterior palatine canal. It is usually found in the midline of the maxillary teeth and in the just posterior of the maxillary incisor teeth [17]. The anterior oral opening of the canal is known as incisive foramen (IF) and usually located just below the incisive papillae 4-5 mm behind the two central teeth. The nasal openings of canal are referred as Stenson's foramina (SF) [33]. The canal includes the terminal branch of the nerve and nasopalatine artery, as well as fibrous connective tissue, fat tissue and small salivary glands [20]. In addition, bone septum may be also seen in the canal [1].

In the literature, difficulties and anatomic limitations related to the location of NPC during placement of implants in anterior maxillary region have been reported [22, 25]. Recently, some researchers have also argued that implantation in the NPC as a viable treatment approach in the rehabilitation of severely atrophic maxilla [3, 22].

Traditionally, two-dimensional methods such as intraoral radiography and panoramic imaging have been proposed in the literature for diagnostic imaging of the anterior maxilla, but they may not be sufficient to show anatomic variations because of their magnification and distortion. Recently, cone-beam computed tomography (CBCT) has allowed detailed three-dimensional (3D) evaluations of anatomical configurations of the various anatomical structures $[10,26,35,38,43,45]$ and determination of the degree of resorption of buccal bone thickness (BBT) in the anterior maxillary region after tooth loss in detail $[7,44]$. It is important to bear in mind that the NPC can occupy 58\% of the BBT [25], and the 3D anatomical features of the NPC need to be precisely defined to ensure safe and accurate surgical planning and placement of dental implants [38]. The anterior maxillary region has a strong influence on surgery, dental and facial aesthetics and function. Surgical procedures involving this region may affect the personal appearance of the patient, along with the psychological and sociological consequences to the patient. In conclusion, it is important to evaluate the position, morphology and dimensions of NPC in order to optimise surgical planning, to establish theories that can explain the aetiopathogenesis of lesions in this anatomic region, and to prevent pos- sible complications (vascular and nerve branching injuries) $[8,16,26,38]$.

In this regard, the aim of current study was to analyse in three dimensions the anatomical and morphometric dimensions of NPC in the coronal, axial and sagittal directions using $C B C T$ and to evaluate the effect of age, gender and maxillary dental status on NPC and BBT.

\section{MATERIALS AND METHODS}

\section{Study design and sample selection}

This retrospective study was approved by the $\mathrm{Hu}$ man Research Ethics Committee of the Faculty of Dentistry, Necmettin Erbakan University, Konya, Turkey (approved no: 2017.08). A total of 619 adult patients (354 female and 265 male) aged between 17 and 86 who applied to the Necmettin Erbakan University, Faculty of Dentistry between 2014 and 2017 and had CBCT scan taken for various diagnostic purposes such as dental implants, implanted teeth, oral pathology were retrospectively evaluated (Table 1 ). All images were evaluated by one maxillofacial radiologist (S.H.). In order to assess intra-observer consistency, $20 \%$ of the measurements were re-evaluated and recorded as blinds to the first measurements after 3 weeks.

CBCT data with the high quality of patients aged 17 years and older were included in the study. The patients with severe atrophy, residual roots, cleft palate, jaw fractures, a pathologic lesion in the premaxillar region, receiving orthodontic treatment or orthodontic surgery, embedded teeth were excluded from the study.

The age of the individuals in the sample group was determined according to the date at which the CBCT scan was taken. The subjects were classified according to their age: group 1 was between the ages of 17 and 30, group 2 was between the ages of 31 and 45 , group 3 was between the ages of 46 and 60 , and group 4 was above the age of 61 . The gender of the individuals was recorded. In addition, individuals were classified and recorded in three groups according to their dental status: group 1: individuals with present both two maxillary central incisors; group 2: individuals with missing one of their two central incisors; group 3: individuals with missing both maxillary central incisors or total edentulous.

\section{Assessment of the images}

$\mathrm{CBCT}$ records of all patients were obtained with 3D Accuitomo 170 (Morita MFG Corp., Kyoto, Japan). 
Table 1. The distribution of individuals according to gender, age groups and dental status

\begin{tabular}{lcccccccc}
\hline Gender & \multicolumn{3}{c}{ Dental status } & \multicolumn{4}{c}{ Age groups } & Total \\
\cline { 2 - 8 } & Group 1 & Group 2 & Group 3 & Group 1 & Group 2 & Group 3 & Group 4 & \\
\hline Female & 263 & 31 & 60 & 63 & 85 & 127 & 79 & 354 \\
Male & 199 & 22 & 44 & 52 & 57 & 92 & 64 & 265 \\
Total & 462 & 53 & 104 & 115 & 142 & 219 & 143 & 619 \\
\hline
\end{tabular}

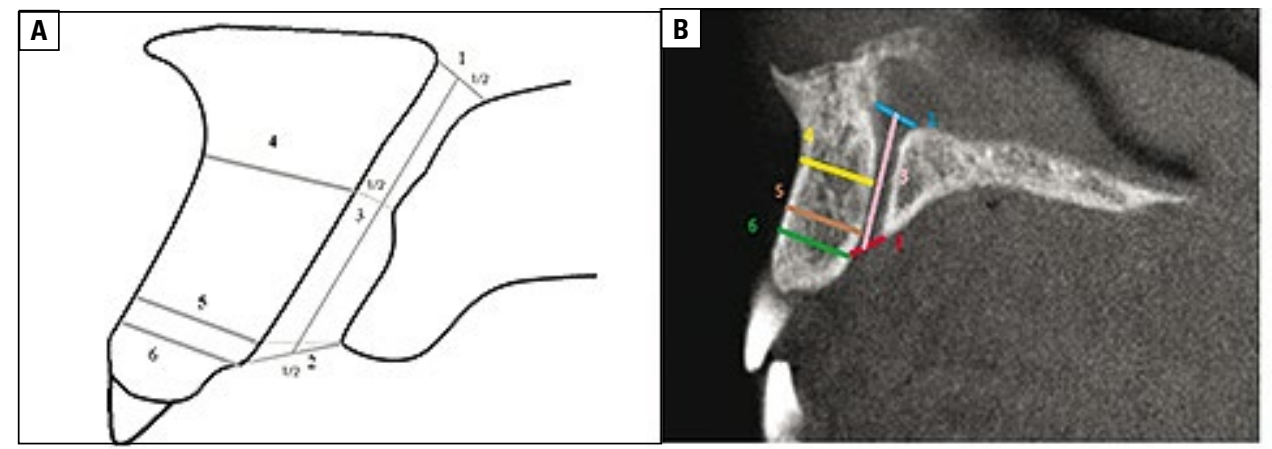

Figure 1. The measurements were shown in a schematic diagram (A) and a sagittal cone beam computed tomography image (B). 1 - the diameter of Stenson's foramina; 2 - the diameter of incisive foramen; 3 - the length of nasopalatine canal; 4 - the measurement of BBT1; 5 - the measurement of BBT2; 6 - the measurement of BBT3.

All scans were performed within the framework of a strict standard protocol $(90 \mathrm{kVp}, 5 \mathrm{~mA}, 17.5 \mathrm{~s}$, isotropic voxel), with the patients positioned in a sitting position, specially crafted headbands and jaws stabilised, parallel to Frankfurt horizontal plane. Images taken at 5 different field of view ranges were used in the study $(170 \times 120 \mathrm{~mm}, 100 \times 100 \mathrm{~mm}, 80 \times$ $\times 80 \mathrm{~mm}, 60 \times 60 \mathrm{~mm}, 40 \times 40 \mathrm{~mm}$ ). The images in which the premaxillar region was retrieved and the NPC and BBT boundaries were within the displayed field were included in the study. The images were analysed in $0.125 \mathrm{~mm}$ cross-sectional intervals using multiplanar reforming sections were closely aligned with specialised computer software (i-Dixel Version 1.8, Morita, Tokyo, Japan).

\section{Analyses of morphometric dimensions and variations of NPC}

The anteroposterior diameters of the SF or IF, and the length of the NPC were measured in millimetres using the reformatted sagittal CBCT images according to Bornstein et al. [5]. If the NPC had two or more nasal and oral openings, all the anteroposterior diameters of visible foramen were summed. The length of the NPC was measured by the line drawn from the midpoint of SF to the midpoint of IF. Regarding
Y-shaped canals and two parallel cylindrical canals seen in the cross-sectional images, the heights of the canal were assessed as the mean value of the heights of the canals (Fig. 1). The shapes of the canal were examined in sagittal sections and classified into six groups based on the classification of Etoz and Sisman [10]: (1) hourglass-like, (2) cone-like, (3) funnel-like, (4) banana-like, (5) cylindrical, and (6) tree branchlike (Fig. 2A-F). BBTs were measured from the portion corresponding to the midpoint of the NPC (BBT1), from the portion corresponding to the cortical border point of the IF on the palatal bone (BBT2), and from the corresponding portion of the alveolar bone originating from the IF (BBT3) (Fig. 1, see points 4-6).

\section{Statistical analysis}

All statistical analyses were performed using the IBM SPSS Statistics 21 (SPSS Company, Illinois, USA) programme. Descriptive statistical evaluations were calculated for all measurements (mean, standard deviation, minimum and maximum values, etc.). Kolmogorov-Smirnov, Mann-Whitney $U$, Kruskal-Wallis and $\chi^{2}$ test was used. The intra-observer reliability and kappa coefficient were calculated. The results were evaluated at $95 \%$ confidence interval; significance level was assumed at $p<0.05$. 

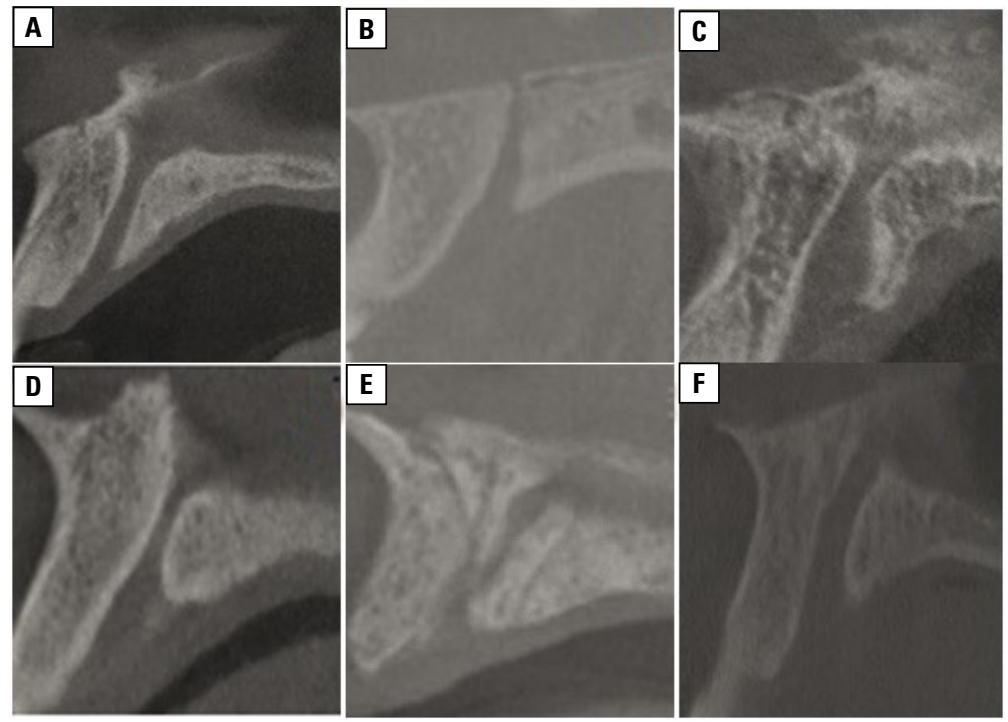

Figure 2. The classification of nasopalatine canal shape in sagittal cone beam computed tomography images; A. Cylinder; B. Cone; C. Funnel; D. Hourglass; E. Tree branch; F. Banana.

Table 2. The mean values of nasopalatine canal (NPC) dimensions according to NPC shapes

\begin{tabular}{lcccccccc}
\hline Canal shapes & N & SF diameter & IF diameter & Canal length & BBT1 & BBT2 & BBT3 & P \\
\hline Cylinder & 104 & 388.4 & 286.87 & 235.35 & 269.49 & 297.89 & 300.36 & \\
Conical & 162 & 243.12 & 314.69 & 311.05 & 341.14 & 337.05 & 319.83 & \\
Funnel & 98 & 193.62 & 378.47 & 325.82 & 324.46 & 249.17 & 244.82 & $0.000^{*}$ \\
Hourglass & 153 & 439.84 & 314.88 & 286.97 & 319.54 & 329.15 & 333.84 & \\
Tree branch & 33 & 198.02 & 259.26 & 411.68 & 219.5 & 270.82 & 296.45 & 347.65 \\
Banana & 69 & 279.79 & 250.06 & 400.01 & 299.54 & 327.41 & & \\
\hline
\end{tabular}

${ }^{*} \mathrm{p}<0.01 ; \mathrm{IF}$ - incisive foramen; SF — Stenson's foramina

\section{RESULTS}

In this study, a total of 994 CBCT images were evaluated for NPC. However, it was found that 346 NPC were blocked or not fully monitored. For this reason, morphological variations and other dimensional evaluations of NPC were performed on 619 images. Our study group consisted of 265 men (mean $47.67 \pm$ \pm 17.17 years) and 354 women (mean $47.48 \pm 15.63$ years) with age ranging from 17 to 87 years (mean $47.57 \pm 16.29$ years). Distribution of individuals according to their dental status and age groups was given in Table 1. There were no statistically significant difference in terms of age groups and dental status between males and females ( $p=0.964$ and 0.970 , respectively).

The reliability Cronbach's alpha values for SF and IF diameters, canal length, BBT1, BBT2 and BBT3 were $0.922,0.918,0.964,0.918,0926,0.934$, respectively. For the NPC shapes, the kappa value was 0.935 .
Of the 619 individuals, $162(26.17 \%)$ were conical, 153 (24.71\%) hourglass, 104 (16.80\%) cylinders, 98 (15.83\%) funnels, 69 (11.14\%) bananas and 33 $(5.33 \%)$ had NPC in the form of a tree. While the most common shapes of NPC were cone-shaped in females (96 individuals, $27.11 \%$ ), males had more hourglassshaped NPC (70 individuals, $24.91 \%$ ). The gender had no statistical influence on NPC shapes $(p>0.05)$. In Table 2, NPC patterns were given by gender, age group and dental status. When the canal form was evaluated according to age, the individuals in group 3 had more prevalent conical, hourglass and banana type of NPC shapes. NPC formations did not show a statistically significant difference according to age groups ( $p>0.05$ ). There was a statistically significant difference in the shape of the canal compared to the dental status $(p<0.01)$. Whereas the conical, funnel and hourglass shapes were observed mostly in the case of missing both central incisors or total 
Table 3. The distributions of nasopalatine canal shapes according to gender, age and dental status; ${ }^{*} p<0.01$

\begin{tabular}{|c|c|c|c|c|c|c|c|c|c|c|c|c|c|}
\hline \multirow[t]{2}{*}{ Canal shapes } & \multicolumn{2}{|c|}{ Gender } & \multirow[t]{2}{*}{$\mathbf{P}$} & \multicolumn{4}{|c|}{ Age groups } & \multirow[t]{2}{*}{$\mathbf{P}$} & \multicolumn{3}{|c|}{ Dental status } & \multirow[t]{2}{*}{ Total } & \multirow[t]{2}{*}{$\mathbf{P}$} \\
\hline & Female & Male & & Group 1 & Group 2 & Group 3 & Group 4 & & Group 1 & Group 2 & Group 3 & & \\
\hline Cylinder & 64 & 40 & & 23 & 25 & 35 & 21 & & 79 & 12 & 13 & 104 & \\
\hline Conical & 96 & 66 & & 29 & 39 & 59 & 35 & & 121 & 12 & 29 & 162 & \\
\hline Funnel & 59 & 39 & & 11 & 16 & 36 & 35 & & 60 & 10 & 28 & 98 & \\
\hline Hourglass & 83 & 70 & 0.520 & 31 & 39 & 50 & 33 & 0.209 & 113 & 12 & 28 & 153 & $0.002^{*}$ \\
\hline Tree branch & 15 & 18 & & 8 & 5 & 11 & 9 & & 26 & 4 & 3 & 33 & \\
\hline Banana & 37 & 32 & & 13 & 18 & 28 & 10 & & 63 & 3 & 3 & 69 & \\
\hline Total & 354 & 265 & & 115 & 142 & 219 & 143 & & 462 & 53 & 104 & 619 & \\
\hline
\end{tabular}

Table 4. The mean values of nasopalatine canal dimensions according to the general, gender, age group and dental status

\begin{tabular}{lcccccc}
\hline & SF diameter & IF diameter & Canal length & BTT1 & BTT2 & BTT3 \\
\hline $\begin{array}{l}\text { General } \\
\text { Gender: }\end{array}$ & 3.49 & 6.08 & 13.64 & 7.54 & 6.41 & 5.93 \\
Female & & & & & & \\
Male & 3.47 & 6.01 & 12.83 & 7.29 & 6.16 & 5.77 \\
p & 3.54 & 6.21 & 14.74 & 7.9 & 6.79 & 6.29 \\
Age group: & 0.247 & 0.098 & $0.000^{*}$ & $0.000^{*}$ & $0.000^{*}$ & $0.009^{*}$ \\
Group 1 & & & & & \\
Group 2 & 3.51 & 5.91 & 14.10 & 8.14 & 7.16 & 6.92 \\
Group 3 & 3.64 & 6.00 & 13.62 & 7.65 & 6.65 & 6.40 \\
Group 4 & 3.49 & 6.14 & 13.62 & 7.40 & 6.23 & 5.67 \\
p & 3.34 & 6.22 & 13.34 & 7.19 & 5.84 & 5.06 \\
Dental status: & 0.276 & 0.299 & 0.328 & $0.000^{*}$ & $0.000^{*}$ & $0.000^{*}$ \\
Group 1 & & & & & \\
Group 2 & 3.46 & 6.10 & 13.93 & 7.73 & 6.73 & 6.43 \\
Group 3 & 3.89 & 6.05 & 13.61 & 6.91 & 5.91 & 5.22 \\
p & 3.42 & 6.00 & 12.37 & 7.07 & 5.25 & 4.09 \\
\hline
\end{tabular}

${ }^{*} \mathrm{p}<0.01$; IF — incisive foramen; SF — Stenson's foramina

edentulous, the rate of appearance of the cylinder, tree branch and banana shapes was decreased as the tooth loss increased (Table 3 ).

It was observed that all measurements showed statistically significant difference according to NPC forms ( $p<0.01$ ). According to this, while the SF diameter was wider in individuals with an hourglassshaped NPC, the IF diameter was found larger in individuals with the funnel-shaped NPC. The average longest canal length was found in individuals with NPC in the form of a tree branch, and the shortest was observed in individuals with cylinder shaped NPC. BBT1 was found to be the least in tree-shaped, and BBT2 and BBT3 were found to be the least in funnelshaped individuals (Table 2).

The mean NPC length in our study was $13.65 \pm$ $\pm 3.12 \mathrm{~mm}(1.93-24.01 \mathrm{~mm})$. Mean NPC length in males was $14.74 \mathrm{~mm}(3.75-24.01 \mathrm{~mm})$ while it was $12.83 \mathrm{~mm}(1.93-21.51 \mathrm{~mm})$ in females. There was a statistically significant difference between males and females in terms of canal length $(p<0.001)$. Although there was a decline in the NPC length due to the decrease of the number of teeth in the individuals after 60 years of age, there was no statistically significant difference in NPC length according to age for both genders $(p<0.05)$. NPC length was statistically significant $(p<0.01)$ both in females and males according to dental status $(p<0.01)$. As the number of teeth in females decreased, the canal length decreased. In males, the canal length was statistically different between the first and second groups but not between the first and thirds groups (Table 4).

The mean IF diameter of all the subjects in our sample group was $6.09 \pm 1.51 \mathrm{~mm}(2.31-11.55 \mathrm{~mm})$ and the SF diameter was $3.49 \pm 1.25 \mathrm{~mm}(1.03-9.52 \mathrm{~mm})$ (Table 4). The mean IF and SF diameters were $6.21 \mathrm{~mm}$ $(2.69-11.55 \mathrm{~mm})$ and $3.53 \mathrm{~mm}(1.03-9.52 \mathrm{~mm})$ in males and $5.99 \mathrm{~mm}(2.31-10.73 \mathrm{~mm})$ and $3.46 \mathrm{~mm}$ $(1.08-8.39 \mathrm{~mm})$ respectively in females (Table 4$)$. It was found that the SF and SF diameters did not show 
a statistically significant difference according to gender, age group and dental status ( $p>0.05$ ) (Table 4).

In our study, the mean BBT1 measurement was $7.54 \pm 1.64 \mathrm{~mm}(1.81-13.63 \mathrm{~mm})$, the BBT2 measurement was $6.41 \pm 1.64 \mathrm{~mm}(2.08-10.69 \mathrm{~mm})$ and the BBT3 measurement was $5.93 \pm 1.75 \mathrm{~mm}(1.27-$ $-11.92 \mathrm{~mm}$ ) (Table 4). In males, the mean BBT1 measurement was $7.90 \mathrm{~mm}(1.81-13.63 \mathrm{~mm})$ while it was $7.28 \mathrm{~mm}(2.81-11.64 \mathrm{~mm})$ in females. The mean BBT2 measurement in males was $6.79 \mathrm{~mm}(2.08-10.40 \mathrm{~mm})$ while it was $6.16 \mathrm{~mm}(2.27-10.69 \mathrm{~mm})$ in females. Mean BBT3 was $6.29 \mathrm{~mm}(1.42-10.80 \mathrm{~mm})$ in males and $5.77 \mathrm{~mm}(1.27-11.92 \mathrm{~mm})$ in females (Table 4). BBT values were statistically significantly different between males and females at all three points (BBT1, BBT2 and BBT3) ( $p<0.001$ for BBT1-2-3). In both genders, BBT1, BBT2 and BBT3 measurements were statistically significant according to age $(p<0.01)$. BBT1, BBT2 and BBT3 values decreased with increasing age (Table 4). In both genders, BBT1, BBT2 and BBT3 measurements showed statistically significant differences according to dental status $(p<0.01)$. As the number of teeth decreased, the values of BT1, BBT2 and BBT3 also decreased (Table 4).

\section{DISCUSSION}

We retrospectively analysed the records of 619 patients with 265 males and 354 females aged 17-87 years (mean $47.57 \pm 16.29$ years). General means of all data were calculated, compared according to gender, age and dental status. The present study indicated that the NPC showed a great deal of variability with regard to its dimensions as well as to its morphological appearance according to gender, age and dental status.

Traditional imaging techniques do not have sufficient confidence in the progression of neurovascular structures in bone [21, 40]. In studies available in the literature that analyse macro- and micro-anatomy of the anterior maxilla, including the course of the nasopalatine nerve and accompanying vessels, it has been reported that computed tomography (CT) $[5,25,26]$, micro-CT $[13,38]$, multidetector computed tomography (MDCT) [14], high-resolution magnetic resonance imaging (HR-MRI) $[17,31]$ have been used. Due to lower radiation doses and lower costs compared to CT, CBCTs, which provide 3D imaging, have been accepted by many dentomaxillofacial authorities as a more accurate and valuable imaging technique [41] and it is popular in the evaluation of anatomical structures such as IF, NPC, mandibular canal and mental foramen $[9,15,32]$. Hence, we evaluated the anatomical and morphological features of NPC and peripheral tissues using CBCT.

In the literature, it was reported that NPC could be seen in various classifications in sagittal and coronal sections [25, 43]. Mardinger et al. [25] classified the NPCs in four groups (hourglass, funnel, banana, cylinder) in the sagittal sections and found that $50.7 \%$ cylindrical, $30.9 \%$ funnel and $14.5 \%$ hourglass NPCs were detected in these groups. Liang et al. [23] grouped NPC shapes under two headings, conical and cylindrical. They reported that whereas conical shape was observed in $3 \mathrm{~mm}$ and shorter canals, cylindrical NPC was detected in $4 \mathrm{~mm}$ and longer canals. Thakur et al. [42] evaluated the NPC shape into two parts as inclined and curved shapes. Etoz and Sisman [10] grouped the canal shape into six groups as tree branch, cylindrical, banana-like, funnel-like, cone-like, and hourglass. In our study group, the conical canals had highest percentage; the results were inconsistency with some studies $[10,25,37,42$, 45]. The reason for these differences may be due to racial diversity and the use of different classification types, sample size, and age. The age and gender had no significant effect on canal shape, which was in accordance with the findings of previous studies [19, $36,37,42]$. However, the dental status had strong effect on NPC shapes in contrary to previous studies $[4,28,38]$. These differences may result from small sample sizes, non-homogenous distribution of tooth groups and the use of different imaging modalities such as micro-CT. In addition, there were statistical differences between all morphometric dimensions of NPC and canal shapes. To the best of our knowledge, our study was the only study that evaluated the relationship between morphometric measurements and canal shapes.

In the literature, it has been reported that the mean canal length is between 8.1 and $16.33 \mathrm{~mm}[25$, 43]. In the present study, NPC length was $13.64 \mathrm{~mm}$ $(1.93-24.01 \mathrm{~mm})$. NPC length was statistically higher in males than females. This result was similar with previous studies [1, 2, 29, 34, 36, 42, 43]. The greater length of NPC in males than females may be due to the fact that males have relatively large craniocaudal dimensions [42]. Bornstein et al. [5] and Etoz and Sisman [10] reported that the NPC length was higher at younger ages and decreased as the age increased. However, NPC length did not show any significant 
difference with age in the current study. This result was in accordance with studies conducted by Thakur et al. [42], Panjnoush et al. [29], Acar and Kamburoglu [1] and Safi et al. [36]. Liang et al. [23], Etoz and Sisman [10], Ozcakir-Tomruk et al. [28], and Song et al. [38] reported that the individuals with teeth had more long NPC length than the edentulous subjects, which this was similar to our result.

The If diameter was generally estimated to be less than $6 \mathrm{~mm}$ and pathologic possibilities should be considered when it exceeds $10 \mathrm{~mm}$ [26]. On the other hand, it was reported that the average diameter of NPC cysts was about $17.1 \mathrm{~mm}$ [39]. In this study, IF was on average at this limit (mean $6.09 \pm 1.51$ $\mathrm{mm}$ ), but the diameter ranged from 2.31 to 11.55 $\mathrm{mm}$, even if the canal had no pathology. The mean SF width was $3.49 \pm 1.25 \mathrm{~mm}(1.03-9.52 \mathrm{~mm})$. In the literature, it has been reported that the average

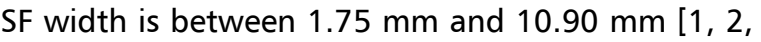
$12,19,36,37]$. In the present study, there were no statistically significant differences between IF and SF diameters according to gender, age groups and dental status. The results obtained according to the gender were similar to the studies performed by Thakur et al. [42], Bornstein et al. [5] and Lopez Jornet et al. [24]. Mardinger et al. [25] stated that the canal was not a static formation but showed dimensional changes with factors such as age and tooth extraction. They theorised that canal diameter increased after tooth extraction. The findings of this study did not support Mardinger's theory [25] consistent with Liang et al. [23] and Tözüm et al. [43]. Tözüm et al. [43] reported that there was alveolar bone resorption after tooth extraction, but that the diameter of the part exposed to resorption remained the same or was smaller. In the following periods, studies with other factors fixed and only evaluated dental status can provide clearer information about the effect of dental status on NPC and surrounding tissues.

In our study, BBTs were evaluated because of the importance of implant surgery in their application to the maxillary anterior tooth missing. BBTs have been measured differently in various studies $[1,5,18,19$, $27,29,42]$. In this study, BBTs were measured at three different points and the means of the measurements were evaluated separately. Studies to date have shown that mean BBT values varies between 3.92 and $12.18 \mathrm{~mm}[1,5,14,18,19,25,27,38,42]$. In our study, the mean BBT1 measurement was $7.54 \pm$ $\pm 1.64 \mathrm{~mm}(1.81-13.63 \mathrm{~mm})$, the BBT2 measurement was $6.41 \pm 1.64 \mathrm{~mm}(2.08-10.69 \mathrm{~mm})$ and the BВT3 measurement was $5.93 \pm 1.75 \mathrm{~mm}(1.27-11.92 \mathrm{~mm})$ in accordance with the intervals ( 3.92 and $12.18 \mathrm{~mm}$ ) stated in the literature. Statistically significant differences were found between males and females (BBT1-2-3), $p<0.001$ ) for all measurements of BBT. Males had wider BBTs than females, in accordance with the previous studies $[1,5,10,18,19,29,36$, 42]. These findings suggest that more precautions should be taken during surgical procedures in female patients. In addition, researchers reported that aging caused decreasing in bone thickness of the anterior maxilla, and some were concerned with the possibility of losing the anterior teeth as their age increased $[25,43]$. As an unusual finding in this study, even in full dentulous individuals, as individuals age increased, there was a decrease in BBT. Although the exact cause is unknown, this may be related to bone remodelling and increased structural loss with age progression. When surgery was planned in the anterior maxillary region, the effect of the tooth condition should be taken into account, especially in relation to the dimensions of buccal bone structures. Peñarrocha et al. [30] reported significant vertical and horizontal resorption in the bone after tooth loss in the anterior maxilla. However, they have emphasized the presence of intense cortical bone even in severe resorption in the anterior area of NPC and suggested that the remaining bone around the nasopalatine nerve canal should be used in patients with severe maxillary atrophy for the implantation. However, our results indicated that there were significant morphological variations of the anatomy of the NPC. As the number of teeth decreased, the values of BBT1, BBT2 and BBT3 also decreased, which is in line with studies conducted by Fernandez-Alonso et al. [11], Etoz and Sisman [10] and Bornstein et al. [5]. According to the results of our study, we can say that the channel is located more anteriorly after tooth loss. These results are also very important for implant surgery.

The present study indicated that the NPC showed a great deal of variability with regard to its dimensions as well as to its morphological appearance according to gender, age and dental status. Nevertheless, there were some restrictions in this study. First, it was a retrospective analysis. Second, the dental status was not homogenous in our sample. Studies with homogeneous tooth groups can provide clearer in- 
formation about the effect of dental status on NPC and surrounding tissues.

\section{CONCLUSIONS}

Results from this study showed that tooth loss in the anterior region did not affect the IF and SF diameters, but affected the NPC shape, NPC length, and BBTs. While age was not an effective factor in NPC shape and morphology, gender was effective only on NPC length. Since BBTs were affected both by gender, age, and dental status, it should be taken into account that the bone thickness of the alveolar bone was not a stable structure in the surgical procedures to be performed in this region. These anatomical changes in terms of dimensional and morphological parameters revealed the importance of 3D imaging. We think that there was a need for extensive radiological, histological and anatomical studies in which anatomic formations of the maxillofacial region were examined in order to prevent unnecessary surgery due to misdiagnosis. Dentists should know and consider the variations in this canal in order to avoid possible complications during anaesthesia and surgical procedures which were applied to the maxillary anterior region. More precautions should be taken during surgical procedures in females, elderly and edentulous patients.

\section{REFERENCES}

1. Acar B, Kamburoğlu K. Morphological and volumetric evaluation of the nasopalatinal canal in a Turkish population using cone-beam computed tomography. Surg Radiol Anat. 2015; 37(3): 259-265, doi: 10.1007/s00276-0141348-9, indexed in Pubmed: 25038838.

2. Al-Amery SM, Nambiar P, Jamaludin M, et al. Cone beam computed tomography assessment of the maxillary incisive canal and foramen: considerations of anatomical variations when placing immediate implants. PLoS One. 2015; 10(2): e0117251, doi: 10.1371/journal.pone.0117251, indexed in Pubmed: 25679505.

3. Artzi Z, Nemcovsky CE, Bitlitum I, et al. Displacement of the incisive foramen in conjunction with implant placement in the anterior maxilla without jeopardizing vitality of nasopalatine nerve and vessels: a novel surgical approach. Clin Oral Implants Res. 2000; 11(5): 505-510, indexed in Pubmed:11168243.

4. Asaumi R, Kawai T, Sato I, et al. Three-dimensional observations of the incisive canal and the surrounding bone using cone-beam computed tomography. Oral Radiol. 2010; 26(1): 20-28, doi: 10.1007/s11282-010-0039-4.

5. Bornstein $M M$, Balsiger $R$, Sendi $P$, et al. Morphology of the nasopalatine canal and dental implant surgery: a radiographic analysis of 100 consecutive patients using limited cone-beam computed tomography. Clin Oral Implants Res. 2011; 22(3): 295-301, doi: 10.1111/j.16000501.2010.02010.x, indexed in Pubmed: 21039896.
6. Buser D, Martin W, Belser UC. Optimizing esthetics for implant restorations in the anterior maxilla: anatomic and surgical considerations. Int J Oral Maxillofac Implants. 2004; 19 Suppl: 43-61, indexed in Pubmed: 15635945.

7. Cawood JI, Howell RA. A classification of the edentulous jaws. Int J Oral Maxillofac Surg. 1988; 17(4): 232-236, indexed in Pubmed: 3139793.

8. Chatriyanuyoke $\mathrm{P}$, Lu Cl, Suzuki $\mathrm{Y}$, et al. Nasopalatine canal position relative to the maxillary central incisors: a cone beam computed tomography assessment. J Oral Implantol. 2012; 38(6): 713-717, doi: 10.1563/AAID-JOID-10-00106, indexed in Pubmed: 20932126.

9. Cohenca N, Simon JH, Roges R, et al. Clinical indications for digital imaging in dento-alveolar trauma. Part 1: traumatic injuries. Dent Traumatol. 2007; 23(2): 95-104, doi: 10.1111/j.1600-9657.2006.00509.x, indexed in Pubmed: 17367457.

10. Etoz M, Sisman Y. Evaluation of the nasopalatine canal and variations with cone-beam computed tomography. Surg Radiol Anat. 2014; 36(8): 805-812, doi: 10.1007/s00276014-1259-9, indexed in Pubmed: 24488202.

11. Fernández-Alonso A, Suárez-Quintanilla JA, RapadoGonzález $\mathrm{O}$, et al. Morphometric differences of nasopalatine canal based on 3D classifications: descriptive analysis on CBCT. Surg Radiol Anat. 2015; 37(7): 825-833, doi: 10.1007/s00276-015-1470-3, indexed in Pubmed: 25821035.

12. Friedrich RE, Laumann F, Zrnc T, et al. The nasopalatine canal in adults on cone beam computed tomograms: a clinical study and review of the literature. In Vivo. 2015; 29(4): 467-486, indexed in Pubmed: 26130792.

13. Fukuda M, Matsunaga S, Odaka K, et al. Three-dimensional analysis of incisive canals in human dentulous and edentulous maxillary bones. Int J Implant Dent. 2015; 1(1): 12, doi: 10.1186/s40729-015-0012-4, indexed in Pubmed: 27747634.

14. Gönül Y, Bucak A, Atalay Y, et al. MDCT evaluation of nasopalatine canal morphometry and variations: An analysis of 100 patients. Diagn Interv Imaging. 2016; 97(11): 1165-1172, doi: 10.1016/j.diii.2015.11.012, indexed in Pubmed: 26797526.

15. Honda K, Arai Y, Kashima M, et al. Evaluation of the usefulness of the limited cone-beam CT (3DX) in the assessment of the thickness of the roof of the glenoid fossa of the temporomandibular joint. Dentomaxillofac Radiol. 2004; 33(6): 391-395, doi: $10.1259 / \mathrm{dmfr} / 54316470$, indexed in Pubmed:15665233.

16. Jacob S, Zelano B, Gungor A, et al. Location and gross morphology of the nasopalatine duct in human adults. Arch Otolaryngol Head Neck Surg. 2000; 126(6): 741-748, indexed in Pubmed: 10864112.

17. Jacobs $R$, Lambrichts I, Liang $X$, et al. Neurovascularization of the anterior jaw bones revisited using high-resolution magnetic resonance imaging. Oral Surg Oral Med Oral Pathol Oral Radiol Endod. 2007; 103(5): 683-693, doi: 10.1016/j.tripleo.2006.11.014, indexed in Pubmed: 17320428.

18. Jain NV, Gharatkar AA, Parekh BA, et al. Three-Dimensional analysis of the anatomical characteristics and dimensions of the nasopalatine canal using cone beam computed tomography. J Maxillofac Oral Surg. 2017; 16(2): 197-204, doi: 10.1007/s12663-016-0879-5, indexed in Pubmed: 28439161. 
19. Kajan ZD, Kia J, Motevasseli S, et al. Evaluation of the nasopalatine canal with cone-beam computed tomography in an Iranian population. Dent Res J (Isfahan). 2015; 12(1): 14-19, indexed in Pubmed: 25709669.

20. Keith DA. Phenomenon of mucous retention in the incisive canal. J Oral Surg. 1979; 37(11): 832-834, indexed in Pubmed: 290778.

21. Kohavi D. Demonstration of Unusually Wide Artery in the Maxillary Alveolar Bone Using a Reformatting Program of Computed Tomography: A Case Report. Int J Oral Maxillofac Implants. 1994; 9(4): 444-448.

22. Kraut RA, Boyden DK. Location of incisive canal in relation to central incisor implants. Implant Dent. 1998; 7(3): 221-225, indexed in Pubmed: 9823111.

23. Liang $X$, Jacobs $R$, Martens W, et al. Macro- and microanatomical, histological and computed tomography scan characterization of the nasopalatine canal. J Clin Periodontol. 2009; 36(7): 598-603, doi: 10.1111/j.1600051X.2009.01429.x, indexed in Pubmed: 19538333.

24. López Jornet P, Boix P, Sanchez Perez A, et al. Morphological Characterization of the Anterior Palatine Region Using Cone Beam Computed Tomography. Clin Implant Dent Relat Res. 2015; 17 Suppl 2: e459-e464, doi: 10.1111/ cid.12271, indexed in Pubmed: 25263847.

25. Mardinger O, Namani-Sadan N, Chaushu G, et al. Morphologic changes of the nasopalatine canal related to dental implantation: a radiologic study in different degrees of absorbed maxillae. J Periodontol. 2008; 79(9): 1659-1662, doi: 10.1902/ jop.2008.080043, indexed in Pubmed: 18771366.

26. Mraiwa N, Jacobs R, Van Cleynenbreugel J, et al. The nasopalatine canal revisited using 2D and 3D CT imaging. Dentomaxillofac Radiol. 2004; 33(6): 396-402, doi: 10.1259/ $\mathrm{dmfr} / 53801969$, indexed in Pubmed: 15665234.

27. Nasseh I, Aoun G, Sokhn S. Assessment of the nasopalatine canal: an anatomical study. Acta Inform Med. 2017; 25(1): 34-38, doi:10.5455/aim.2017.25.34-38, indexed in Pubmed: 28484295.

28. Özçakır-Tomruk C, Dölekoğlu S, Özkurt-Kayahan Z, et al. Evaluation of morphology of the nasopalatine canal using cone-beam computed tomography in a subgroup of Turkish adult population. Surg Radiol Anat. 2016; 38(1): 65-70, doi: 10.1007/s00276-015-1520-x, indexed in Pubmed: 26228382.

29. Panjnoush $M$, Norouzi $H$, Kheirandish $Y$, et al. Evaluation of morphology and anatomical measurement of nasopalatine canal using cone beam computed tomography. J Dent (Tehran). 2016; 13(4): 287-294, indexed in Pubmed: 28127321.

30. Peñarrocha D, Candel E, Guirado JL, et al. Implants placed in the nasopalatine canal to rehabilitate severely atrophic maxillae: a retrospective study with long follow-up. J Oral Implantol. 2014; 40(6): 699-706, doi: 10.1563/AAID-JOID-12-00145, indexed in Pubmed: 23397941.

31. Peñarrocha $M$, Carrillo $C$, Uribe $R$, et al. The nasopalatine canal as an anatomic buttress for implant placement in the severely atrophic maxilla: a pilot study. Int J Oral Maxillofac Implants. 2009; 24(5): 936-942, indexed in Pubmed: 19865635.

32. Pohlenz $P$, Blessmann $M$, Blake $F$, et al. Clinical indications and perspectives for intraoperative cone-beam computed tomography in oral and maxillofacial surgery. Oral Surg Oral Med Oral Pathol Oral Radiol Endod. 2007; 103(3): 412-417, doi: 10.1016/j.tripleo.2006.05.008, indexed in Pubmed:17321455.
33. Radlanski RJ, Emmerich S, Renz H. Prenatal morphogenesis of the human incisive canal. Anat Embryol (Berl). 2004; 208(4): 265-271, doi:10.1007/s00429-004-0389-y, indexed in Pubmed: 15293047.

34. Rodricks D, Gupta A, Phulambrikar T, et al. Anatomical and morphological characterization of the nasopalatine canal: a cone-beam computed tomography study. Mymensingh Med J. 2016; 25(2): 349-356, indexed in Pubmed: 27277370.

35. Rodrigues MT, Munhoz EA, Cardoso CL, et al. Unilateral patent nasopalatine duct: a case report and review of the literature. Am J Otolaryngol. 2009; 30(2): 137-140, doi: 10.1016/j.amjoto.2008.02.015, indexed in Pubmed: 19239956.

36. Safi Y, Moshfeghi M, Rahimian S, et al. Assessment of nasopalatine canal anatomic variations using cone beam computed tomography in a group of iranian population. Iran J Radiol. 2016; 14(1), doi: 10.5812/ iranjradiol.37028.

37. Sekerci AE, Cantekin K, Aydinbelge M. Cone beam computed tomographic analysis of neurovascular anatomical variations other than the nasopalatine canal in the anterior maxilla in a pediatric population. Surg Radiol Anat. 2015; 37(2): 181-186, doi: 10.1007/s00276-014-1303-9, indexed in Pubmed:24789202.

38. Song WC, Jo DI, Lee JY, et al. Microanatomy of the incisive canal using three-dimensional reconstruction of microCT images: an ex vivo study. Oral Surg Oral Med Oral Pathol Oral Radiol Endod. 2009; 108(4): 583-590, doi: 10.1016/j. tripleo.2009.06.036, indexed in Pubmed: 19778745.

39. Swanson KS, Kaugars GE, Gunsolley JC. Nasopalatine duct cyst: an analysis of 334 cases. J Oral Maxillofac Surg. 1991; 49(3): 268-271, indexed in Pubmed: 1995816.

40. Temmerman A, Hertelé $S$, Teughels $W$, et al. Are panoramic images reliable in planning sinus augmentation procedures? Clin Oral Implants Res. 2011; 22(2): 189-194, doi: 10.1111/j.1600-0501.2010.02000.x, indexed in Pubmed: 20868452

41. Teughels W, Merheb J, Quirynen M. Critical horizontal dimensions of interproximal and buccal bone around implants for optimal aesthetic outcomes: a systematic review. Clin Oral Implants Res. 2009; 20 Suppl 4: 134-145, doi: 10.1111/j.1600-0501.2009.01782.x, indexed in Pubmed: 19663960.

42. Thakur AR, Burde K, Guttal K, et al. Anatomy and morphology of the nasopalatine canal using cone-beam computed tomography. Imaging Sci Dent. 2013; 43(4): 273-281, doi: 10.5624/isd.2013.43.4.273, indexed in Pubmed: 24380067.

43. Tözüm TF, Güncü GN, Yıldırım YD, et al. Evaluation of maxillary incisive canal characteristics related to dental implant treatment with computerized tomography: a clinical multicenter study. J Periodontol. 2012; 83(3): 337-343, doi: 10.1902/jop.2011.110326, indexed in Pubmed: 21910596.

44. Van der Weijden F, Dell'Acqua F, Slot DE. Alveolar bone dimensional changes of post-extraction sockets in humans: a systematic review. J Clin Periodontol. 2009; 36(12): 1048-1058, doi: 10.1111/j.1600-051X.2009.01482.x, indexed in Pubmed: 19929956.

45. Von Arx T, Bornstein MM. [The patent nasopalatine duct. A rare anomaly and diagnostic pitfall]. Schweiz Monatsschr Zahnmed. 2009; 119(4): 379-389, indexed in Pubmed: 19485076. 